\title{
ADSORÇÃO DE CÁDMIO EM SOLO PODZÓLICO VERMELHO AMARELO - ORTO E GLEI HÚMICO DA REGIÃO DO VALE DO RIBEIRA - SP E TERRA ROXA ESTRUTURA DO MUNICÍPIO DE PIRACICABA - SP
}

\author{
SATORU OMAE
}

Orientador: Prof. Dr. TOSHIAKI KINJO

Dissertação apresentada à Escola Superior de Agricultura "Luiz de Queiroz", da Universidade de São Paulo, para obtenção do Título de Mestre em Agronomia. Área de Concentração: Solos e Nutrição de Plantas.

$P \mid R A C I C A B A$

Estado de São Paulo - Brasil

Novembro de 1984 
.ii.

OFERECO

A minha mae

A minha sogra. 
. i i i.

DEDICO

A minha esposa HIDEKO
e aOs meus filhos
ALEXIS, ELOCY e MIRNA 
. iv.

A memória de meu pai, sogro, irmão e minhas cunhadas. 


\section{AGRADECIMENTOS}

- Ao Prof. Dr. Toshiaki Kinjo, pela orientação segura, amizade e apoio prestado durante o curso e na realização des te trabalho;

- Aos Professores do Curso de Pós-Graduação pela orientação segura e eficiência nos cursos realizados;

- Aos Senhores Funcionários da Biblioteca e da Secretaria do Curso de Pós-Graduação da Escola Superior de Agricultü ra "Luiz de Queiroz", pela prestimosa atençãodurante o curso;

- Aos Senhores funcionärios da E.S.A. "Luiz de Queiroz", e especialmente do Departaménto de Solos, Geologia e Fertilizantes pela colaboração nas anälises físicas e Químicas das amostras de Solo;

Ao CENA - Centro de Energia Nuclear na Agricultura da Uni versidade de São Paulo, pelas anâlises químicas efetuadas;

- A Escola Superior de Agricultura "Luiz de Queiroz", por todas as facilidades oferecidas no desenvolvimento dos es tudos; 
- A Fundação Armando Alvares Penteado, através dos Senhores Prof. Dr. Roberto Pinto de Souza - Diretor Tesoureiro pela concessão da. Bolsa de Estudos, e Prof. Evaristo Valladares Costa - Presidente do Conselho das Faculdades pela concessão do Laboratório para pesquisas;

- A Faculdade de Engenharia da Fundação Armando Alvares Pen teado, através do seu Diretor Prof. Victor Mirshawka e sua Coordenadora Profa Josefa Alvares Alvares pela licen ça ao Curso de Mestrado;

- Aos Prof. Caetano Billiboni pelo encaminhamento a minha carreira universitäria e Prof. Dr. José Milton Nogueira pelo estímulo ao aperfeiçoamento universitärio;

- Ao Centro de Informātica da FAAP, através do seu Coordena dor Prof. Simpson Simão Kalmus, pelo processamento de dados no computador;

Aos Senhores Funcionärios e Técnicos de Laboratörio da Fundação Armando Alvares Penteado, especialmente aos Srs. Carlos Alberto Portscheler, Orlando Chaves Bitencourt e Salvador Galego no auxílio a montagem das experiências e extração das amostras;

- A todos que direta ou indiretamente, contribuíram para a realização deste trabalho. 
ADSORÇ̃̃O DE CÁDMIO EM SOLO PODZÓLICO VERMELHO AMARELO-ORTO, GLE I HÚMICO. DA REGIÃO DO VALE DO RIBEIRA - SP

E TERRA ROXA ESTRUTURADA DO MUNICIPIO DE PIRACICABA - SP

AUTOR: Satoru Omae

ORIENTADOR: Prof. Dr. Toshiaki Kinjo

\section{RESUMO}

Utilizando solos do litoral Paulista no Va le do Ribeira de uma ärea antes nunca cultivada, com solos Podzólicos Vermelho Amarelo-orto e Glèi Húmico do município de Juquia e amostras de Terra Roxa Estruturada do Município de Piracicaba - SP, conduziu-se um experimento de adsorção com o Cảdmio. A metodologia adotada na condução da adsorção do câdmio foi a de John (1972) aplicando a isoterma de Lang muir. A adsorção foi verificada até 1.000 ppm de cädmio, o nivel mais al to do experimento tendo melhor aplicabilidade da equação de Langmuir em soluções de baixas concentrações atê $100 \mathrm{ppm}$ tendo o coeficiente de correlação $r=1,00$. A este nível a competição do $C d$ com as principais bases do so lo è bastante acentuada. A níveis de concentrações altas do 


\section{. vi i .}

cádmio a tendência deste metal e competir também com $\mathrm{Al}^{3}{ }^{+} \mathrm{e} \mathrm{H}^{+}$. - solo que apresenta maior adsorção em termos de cádmio tro cável fo.i Glei Hụmico e com maior risco de toxidez a planta por Cd, e de menor risco o solo TE. As adsorções iônicas em termos de cảdmio trocävel estão na seguinte ordem:

$$
G H>P V \text {-orto }>T E .
$$


CADMIUM ADSORPTION IN RED-YELLOW PODZOLIC SOIL AND HUMIC-GLEI SOIL FROM RIBEIRA VALLEY (,$\left.P_{.}\right)$

AND IN TERRA ROXA ESTRUTURADA FROM

PIRACICABA COUNTY (S,P.)

\author{
AUTHOR : Satoru Omae
}

ADVISER: Prof. Dr. Toshiaki Kinjo

\title{
SUMMARY
}

The purpose of this study was to evaluate the cadmium adsorption in a Red-Yellow Podzolic soil and a Humic Gley soil, both located in Ribeira Valley SP, collected from an area that has never beem cultivated, and in a Terra Roxa Estruturada from Piracicaba County. The method employed to determine the cadmium adsorption was that proposed by John (1972). Langmuir adsorption isotherm was used to evaluate the cadmium adsorption. It was observed that the cadmium adsorption occurred in all levels of cadmium concentration up to $1.000 \mathrm{ppm}$, which was the highest level of the experiment. Cadmium adsorption is best described by the Langmuir adsorption isotherm when cadmium concentration i.s less than $100 \mathrm{ppm}$. At this level of concentration cadmium 
competition with exchangeable bases is pretty much accentuated. A higher levels of concentration, cadmium tends to compete with exchangeable.A ${ }^{3}+$ as well. Among three soils studied, Humic-gley soil has the largest adsorption of cadmium as exchangeable and the greatest risk of cadmium toxicity to plants and Terra Roxa Estruturada soil seems to be less hazardous. Adsorption of cadium as exchangeable in the soils studied decrease in the following order:

\footnotetext{
Humic-glei soil > Red-Yellow Podzolic soil > Terra Roxa Estruturada
} 
$\cdot x i$.

\section{SUMĂR IO}

Página

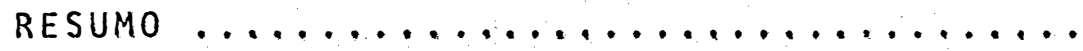

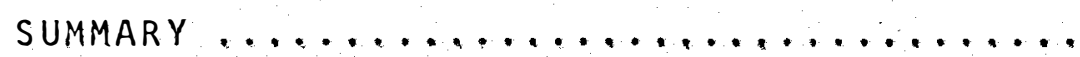

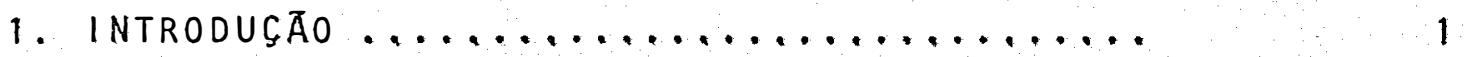

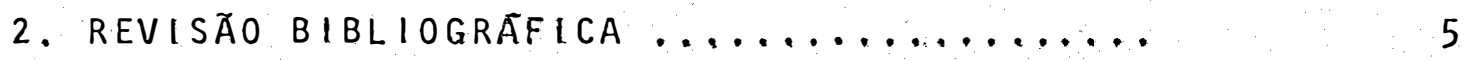

2.1. Metais pesados .............. 5

2.2. Adsorção do cãdmio $\ldots \ldots \ldots \ldots \ldots \ldots$

3. MATERIAL E METODOS $\ldots \ldots \ldots \ldots \ldots \ldots \ldots \ldots \ldots \ldots \ldots \ldots \ldots$

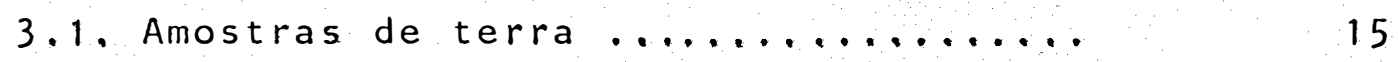

3.2. Adsorção de cãdmio $\ldots \ldots \ldots \ldots \ldots \ldots$

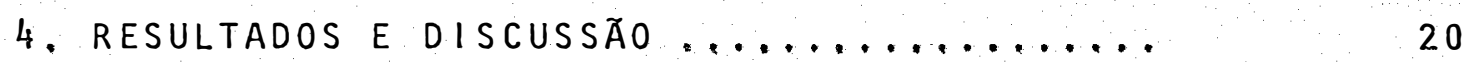

4.1. Análise das adsorções .......... 20

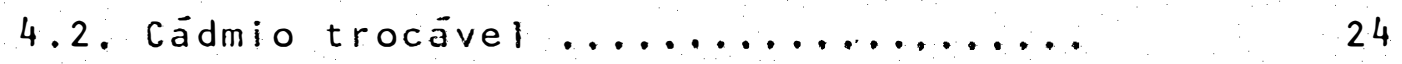

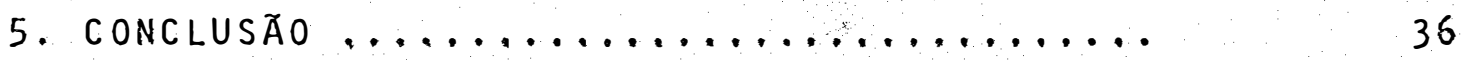

6. LITERATURA CITADA .............. 38 
.xii.

\section{LISTA DE TABELAS}

TABELA NO

Pägina.

1

Alguns resultados da anälise química de solo Podzolico vermelho amarelo orto; glei humico e terra roxa estru

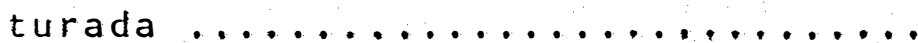

Anālise granulométrica de solos podzolico vermelho amarelo-orto, glei humico e terra roxa estruturada ....

$3 \quad \therefore \quad$ Resultados das análises de adsorção de $c d$ e valores de $x / m$ e $C(x / m)$ e concentraçōes de Cd em amostras de solos podzölico vermelho orto, glei hümico e terra roxa estruturada ....

Equação de Langmuir na forma linear, coeficientes e constante de afinidade nos solos podzölico vermelho orto, glei hümico e terra roxa estruturada.

Relação de saturação \% $c d^{2+}$ trocável vs. CTC efetiva e $\% \mathrm{Cd}^{2+}$ vs $\mathrm{CTC}_{7} \ldots$ 
xii i.

\section{LISTA DE FIGURAS}

FIGURA NQ

Päginà

1

Curva de adsorção de cádmio em solos Podzölico vermelho amarelo-orto,glei hümico e terra roxa estruturada em diferentes níveis de concentração de cảdmio na solução de equilíbrio ....

2

Regressão linear da equação de Langmuir $C /(x / m)$ vs. C com 5 pontos a baixa concentração em solo PV orto.

Regressão linear da equação de Langmuir $\mathrm{C} /(\mathrm{x} / \mathrm{m})$ vs. C com 8 pontos em

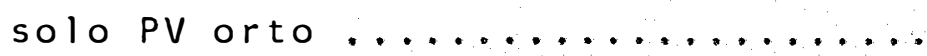

4

Regressão linear da equação de Langmuir $\mathrm{C} /(\mathrm{x} / \mathrm{m})$ vs. C com 5 pontos em baixa concentração no solo glei húmi

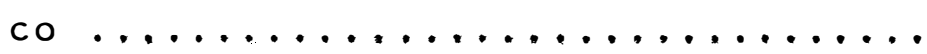

5 Regressão linear da equação de Langmuir $C /(x / m)$ vs. C com 8 pontos em sologlei hümico...............

Regressão linear da equação de Langmuir $\mathrm{C} /(\mathrm{x} / \mathrm{m})$ vs, $\mathrm{C} \operatorname{com} 5$ pontos a baixa concentração em solo TE .....

Regressão linear da equação de Langmuir $\mathrm{C} /(\mathrm{x} / \mathrm{m})$ vs. C com 8 pontos em

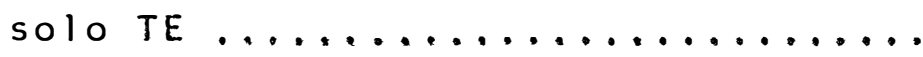




\section{INTRODUÇÃO}

A noção vulgar de poluição ambiental é tida como coisa que afeta os outros e não a nós ou quem polui são outros. Entretanto, as vítimas desta insensatez so mos nös mesmos. E fato sapido desta negligência tanto de örgãos governamentais ou do püblico em geral, fatos como po luição por metais pesados que causaram danos irreparáveis a saúde, incapacidade ao trabalho ou sobrevindo até a morte, como aconteceu com o lançamento indiscriminado pela indústria do composto de mercúrio na Baía de Minamata, Japão, que eram reciclados para o homem, através do consumo de peixes que estavam contaminados com metilmercúrio. 
Nem todos os metais pesados são tóxicos ao homem ou a planta, entrando alguns na essencialidade na com posição química para o metabolismo dos vegetais e animais. Porém, alguns deles para o homem, como mercūrio, chumbo, cädmio e cromo são extremamente töxicos ou são agentes cancerígenos. 0 cádmio causou uma doença reumática conhecida como "Itai-Itai" na cidade Fuchu - Japão em 1947 causando envenenamento crônico por cádmio conforme declarou o Ministērio da Saūde e Bem Estar do Governo Japonês em 1968. Este envenenamento foi causado por via alimentar através de peixes que eram contaminados pela poluição dos dejetos industriais lançados ao mar. Calcula-se que tenham morrido por este envenenamento 100 pessoas até 1965 no Japão.

0s vărios relatos consubstanciados como causadores de câncer, disfunção renal, retardamento intelec tual, degeneração do miocárdio, enfizema pulmonar, bronquites e asmas são provocados pelo metal Cd (SCHOROEDER, 1965).

As plantas absorvem elementos tanto töxicos como essenciais quando expostos em seu habitat.

Hoje, o cádmio é um poluente de alto risco no ambiente portanto a saúde, tanto para os animais ou vege tais. A constante preocupação com este metal tem sido obję to da atenção de diversos autores com grande ênfase em révistas cientificas, destacando-se alguns autores estudiosos 
dessa matēria, como LAGERWERfF (1972), PAGE e BINGHAM (1973) e SCHOROEDER e BALASSA (1961). Através da inalação ou ingestão que são as maneiras pelas quais estes metais entram no nosso organismo, principalmente ao consumirmos al imentos contaminados. As plantas tornam-se contaminadas, pela absorção de cácimio através de solos poluídos por este metal pela adubação, aplicação de pesticida e descartes de resíduos urbanos provenientes de atividades industriais principalmente de metalurgia no tratamento de superfície metálicas. em Galvanoplastia (PAGE e BINGHAM, 1973). As contaminações por via aérea são provocados pelos fornos industriais, moto res a öleo diesel estacionärios, veículos automotores e pelos desgastes de pneus. Estes fatos podem ser comprovados medindo-se as concentraçōes do metal ao redor das áreas da fonte poluente, cujo gradiente de concentração diminue a me dida que se distancia da fäbrica ou da estrada ( LAGERWERFF e SPECHT, 1970 ).

Os experimentos realizados com 23 variedades de plantas cultivadas em solução nutritiva contendo cádmio por Jarvis et alZi (1976) citado por MENGEL e KIRKBY (1978) mostram que muitas espécies absorvem grande quantida de de cādmio. A absorção em algumas espécies são restritos a raízes, outras são translocadas as folhas como em alface (Lactuca sativa). 
Um experimento realizado com o objetivo de comparar a absorção do cädmio pela alface, rabanete e erviIha por RESUS et $\alpha$ li $(1976)$, mostraram que a absorção do cādmio é uma função linear em relação a concentração do cā mio.

Atualmente cogita-se muito na utilização a gricola de lamas de esgotos e resíduos urbanos fermentados. E sabido que ela contëm, embora em baixas concentrações, es tes metais tóxicos poluentes por ser descartes de toda sorte de resíduos industriais e agrícolas. A adicão contínua destes descartes urbanos ao solo haverá um acúmulo contínuo de metais pesados inicialmente na superfície indo até o 1 imite da capacidade de adsorção māxima de cada tipo de solo. Estas adições contínuas em baixa concentração deverá haver uma adsorção pelo solo que poderá competir com as principais bases, cujos níveis são desconhecidos em nosso solo, as sim como em adições a al tas concentrações de cādmio. Basea da nesta hipótese, foi conduzido o experimento para estudar a adsorção de cädmio em diferentes níveis de concentração em solos Podzólico Vermelho Amarelo-orto, Glei Hümico e Ter ra Roxa Estruturada. 


\title{
2. REVISÃO BIBLIOGRÁFICA
}

\author{
2.1 Metais pesados
}

São considerados como "metais pesados", se gundo WHITTON (1975), àqueles metais cuja densidade apresen tam maior que 5,0. Dessa forma o arsênio, berilio, boro, chumbo, cobalto, cobre, cromo, estanho, estróncio, ferro, lí tio, manganês, mercūrio, molibdênio, níquel, prata, selênio e zinco são metais pesados. Em níveis adequados, alguns destes metais são essenciais, tanto no reino vegetal como no animal. São eles: boro, cobalto, cobre, ferro, manganês, molibdênio e zinco. Outros, além de não se enquadrarem nos 
critérios de essencialidade dos organismos vivos, ainda re-

presentam uma séria ameaça aos mesmos, quando presente no meio, em quantidade minima capazes de provocar distúrbios por intoxicação, como é o caso do arsênio, cădmio, chumbo, estanho, mercúrio, cromo e selênio.

\subsection{Adsorção do cādmio}

Atualmente existem värios trabalhos de pes quisas sobre a adsorção do cädmio, envolvendo solos com di-. ferentes caracteristicas físicas e químicas bem como turfa, lama de esgoto com adição de complexantes orgânicos EDTA (Etileno Diamino Tetracetato), NTA (Nitrilo Triacetato), a cetatos e oxalatos.

Um dos trabalhos pioneiros apresentado por JOHN (1972) que estudou a adsorção do metal cädmio em trinta diferentes tipos de solos $(0-16 \mathrm{~cm}$ de profundidade) da Britsh Columbia, com soluções de $1 ; 5 ; 10 ; 50 ; 100 ; 250 ; 500$ e $1000 \mathrm{ppm}$ de $\mathrm{Cd}$. Os resultados foram analisados na equação de Langmuir. Os dados obtidos mostraram que a quantida de de Cd adsorvida $x / m$ aumenta acentuadamente ate 6 horas de agitação, sendo 16 horas o tempo suficiente para atingir 
o equilíbrio e cuja concentração da solução para a aplicab i lidade da equação de Larigmuir é até 100 ppm, também observa dos por OLSEN e WATANABE (1957) no estudo da adsorção do fösforo. Os coeficientes de correlação $r$ apresentaram um valor médio de 0,993 nos 30 solos. Nestas equações, nota-se que as propriedades heterogêneas dos solos faz com que haja variações nas suas correlações. 0 agrupamento em 4 tipos de solos teve os seguintes coeficientes:

$\begin{array}{ll}\text { arenoso } & r=0,995 ; \\ \text { limoso } & r=0,992 ; \\ \text { argiloso } & r=0,997 \mathrm{e} \\ \text { material orgânico } & r=0,82 .\end{array}$

As quatro equações pertencem a um feixe de retas paralelas com interceptos diferentes quando feita a regressão na forma linear $C /(x / m)$ vs C. 0 autor ainda apresenta uma corre lação significativa ao coeficiente da adsorção mäxima b e coeficiente de afinidade $k$ com os teores de zinco e aluminio existente no solo, o que necessitaria de maiores pesqui sas para melhor elucidar.

$$
\text { MILBERG et alii (1978) estudaram a adsor- }
$$
ção iônica do cädmio em relação ao cälcio em solos arenosos, argilosos e siltosos tratados com uma solução de $\mathrm{CaCl}_{2}$. Nes te estudo a quantidade de cädmio trocävel $\left(\mathrm{Cd}_{x}\right)$ foi calcula da medindo-se o decréscimo de concentração na solução e foi 
expressa em porcentagem da capacidade de troca de cations. Assim o cälcio trocāvel ( $\left.\mathrm{Ca}_{x}\right)$ foi calculado:

$$
C a_{x}=\left(C T C-C d_{x}\right)
$$

A constante Ks é calculada pela relação:

$$
K s=\left(C_{x} / C d_{s}\right) \ldots\left(C a_{s} / C a_{x}\right)
$$

onde $\mathrm{Ca}_{s} \mathrm{e} \mathrm{Cd_{s }}$ são.valores das concentrações finais, e a relação $\mathrm{Cd}_{x} / \mathrm{Cd}_{s}$ e $\mathrm{Ca}_{s} / \mathrm{Ca}{ }_{x}$ são as razões de distribuição dos dois ions. Os resultados apresentados pelos autores mostram que a seletividade da adsorção em primeiro lugar é de vida a constituição mineralögica dos solos, sendo maior em solos argilosos e siltosos e menor em solos arenosos mesmo tratados com cálcios. Em solos arenosos para os valores de $C_{x}$ acima de $0,25 \%$ do cädmio adicionado em solo de : $C T C=$ $59 \mu \mathrm{eq} / \mathrm{g}$ o valor de ks médio é de 3,2. Abaixo de 0,25\% o ks é maior do que 4,0 significando o aumento da adsorção de cädmio com o acrēscimo da $\mathrm{CaCl}_{2}$.

$$
\text { Em solo argiloso, } C d_{x} \text { é menor que } 0,30 \%
$$
$(C T C=205 \mu \mathrm{eq} / \mathrm{g})$ e Ks é maior que to. Em solo siltoso é complexo tendo ks mëdio acima de 30 , sendo constante com solo arenoso, diminuindo com o aumento da concentração da $\mathrm{CaCl}_{2}$. Os efeitos da incom pleta dissociação ou do ion complexo na formação do $\mathrm{CdCl}_{2}$ na solução é 
discutida por GARCIA-MIRAGAYA et alii (1976). A presença desse ion na solução em primeiro lugar reduz o nível de Cd e consequente mente o ion $\mathrm{Cd}^{2}+$ resultado em menor adsorção de cädmio. Es te mecanismo é sugerido para explicar a adsorção no solo siltoso mas há dificuldade para explicar a discrepância do solo argiloso e arenoso em condições similares de solução em equilibrio. São grandes as dificuldades de interpreta ção devida a impossibilidade da substituição do Ca totalmen te da solução uma vez que o cädmio poderia estar sendo subs tituido por outros elementos como Mg, K ou Zn. 0 autor a $\underline{\mathrm{I}}$ da pesquisou efeitos da concentração de $\mathrm{NaCl}$ na adsorção do cădmio tendo encontrado que aumentando a concentração do $\mathrm{Na}$ decresce a adsorção de Cd. Em contraste na análise o aumen to de Na aumenta a concentração de Cd sobrenadante na solu ção. Com o aumento da adsorção de Cd aumenta a concentração do NaCl na solução, cujo comportamento é normal na troca iônica.

ELLIOTT e DENNENY (1982) pesquisaram a adsorção de cádmio na presença dos seguintes complexantes: EDTA, NTA, acetato e oxalato em solos arenosos, areno-argiloso e silte-limoso, com finalidade de estudar a adsorção e letrostātica. 0 efeito da redução de adsorção do cádmio é pouco perceptível (até pH 6) pela presença dos compostos or gânicos em todos os tipos de solos. A formação dos comple- 
xos, com diferentes valências, como $\mathrm{CdAc}^{+}, \mathrm{CdOx}^{\circ}, \mathrm{CdNTA}^{-} \mathrm{e}$ CdEDTA $^{2}$ - tem grande influência na adsorção dos metais pesa dos. Destes, somente o complexo do oxalato não será adsorvido eletrostaticamente devido a sua carga ser neutra. A presença de complexos orgânicos, pela análise do trabalho, somente o EDTA sofreu influência na redução da adsorção do cádmio, devido a formação estável do complexo Cd-EDTA. A influência dos complexantes orgânicos sobre os $C d^{2}+1$ ivres tem a seguinte ordem de inibição de adsorção: EDTA > NTA > 0x Ac. Os complexos EDTA e NTA em solo silte-limoso tem pouca influência no pH, porém para os solos arenoso e areno argilosos para pH acima de 6, parece haver competição dos ions presentes. Acima do pH 7 é mais acentuada a influência dos complexos I igantes. Os efeitos competitivos são suger dos por DAVIS e LECKIE (1978) que propuseram dois mecanismos de redução da adsorção quando adicionado o.s complexos ligan tes. A primeira, caso os complexos ligantes não sejam adsorvidos ao adsorvente, ela simplesmente competem na superfície do metal ion. A segunda, se o adsorvato é o complexo I igante formando nücleo central funcional, então a sua superficie ficará envolvida pelo adsorvente ficando indisponí vel ac metal ligante e pode reduzir a adsorção do metal. En tretanto, quantificar os efeitos desta redução é difícil. Fo ram pesquisadas para precisar esta quantidade com àcido hü- 
mico e fülvico, mas os valores são controversos pelos pesquisadores dando a razão estequiométrica de $1: 1$ de Cód àcido fülvico, tendo sido encontrado por TAKAMATSU e YOSHIDA (1978) a constantede $10,5,3$ para pH 5,7 e $10^{6,0}$ para pH 7,7 por BRADY e PAKEMKORF (1978). Nos oxalatos e acetatos pratica mente não houve nenhuma influência, talvez devida a pouca capacidade de ligação iônica para formação do complexo CdAc e $C d-0 x$ ou devida a grande quantidade de matéria orgânica existente, cuja evidência é mais acentuada em solos limo sos. No trabalho apresentado, houve ensaios com excesso de acetatos, podendo confirmar a redução de adsorção. Entretanto, o trabalho mostra a utilidade prática para irrigaça em solos nas condições äcidas ou básicas e com os quelatos para a minimização da contaminação do solo pelo cádmio.

Trabalho semelhante foi realizado por CHUBIN e STREET (1981) utilizando hidröxido de Fe e Al, Nacaolinita e Na-montmorilonita como adsorvente e complexos orgânicos EDTA, citrato e material orgânico retirado das la mas de esgoto de Chicago. Os resultados deste ensaio mosțram em função de $p H$ que as adsorções em $p H<6$ são maiores em hidróxido de Al e Fe dando aproximadamente $50 \%$ de adsorção. Hả uma adsorção sübita nos pH entre 7 e 8 da qual os autores sugerem ser uma característica da curva adsor- 
ção-pH. Em montmorilonita e caolinita o pH maior que 8,0 não se pode distinguir entre adsorção ou precipitação ocorrida. Os efeitos dos complexos orgânicos em hidróxido de alumínio $\mathrm{Al}(\mathrm{OH})_{3}$ somente o citrato a pH abaixo de 7 dimi nui a adsorção em cerca de 15 a $20 \%$ com possível interação do ion $\mathrm{Al}^{3}+$ - citrato, assim como a interação do Cd-citrato, Com a adição do EDTA na solução, o sistema $\mathrm{Al}(\mathrm{OH})_{3}-\mathrm{Cd}^{2+} \operatorname{man}$ tềm o cādmio aproximadamente constante em todos os níveis de pH. Efetivamente hä competição na superfície de $A l(O H)_{3}$ com consequente inibição do $\mathrm{Cd}^{2}+0$. 0 demais complexos orgâ nicos da lama de esgoto não tem apresentado nenhum efeito. os efeitos do citrato em hidröxido de ferro não são verificados como aconteceu em hidróxido de alumínio. Porém a pre sença de EDTA faz a inibição na adsorção, e conforme o autor, é evidente o sistema $\mathrm{Fe}(\mathrm{OH})_{3}-\mathrm{Cd}^{2}+$. Os complexos orgânicos da lama de esgoto tambëm não tem influência. os resultados apresentados nos ensaios de caolinita e montmorilo nita são de que a presença de materiais orgânicos da lama de esgoto e citrato aumentam a adsorção de cādmio. Este fato pode ser devido a formação do complexo organo - argila com alta afinidade por $\mathrm{Cd}^{2+}$. 0 EDTA, como nos outros ensaios apresentam inibição constante entre pH 4 a pH 10 . 
Outros estudos de adsorção do cádmio em mi nerais foram pesquisados por INSKEEP e BAHAN (1983) e FORBES et alii (1976).

INSKEEP e BAHAN (1983) estudaram a adsorção de Cd em Na-montmorilonita e verificaram que a concentração do metal em função do $\mathrm{pH}$, revelou que $\mathrm{H}^{+}$não compete grandemente com o íon metālico para o sítio da adsorção na montmorilonita quando comparado a adsorção pelos óxidos e são poucos significativos a baixo pH. Os valores de equili brio de Cd a alta concentração, empregada na presença de Na montmorilonita confirma que o Cd foi sub-saturado com relação a $\mathrm{Cd}(\mathrm{OH})_{2}$, indicando que a adsorção controla a solubili dade do Cd. No experimento realizado pelos autores a forma ção de $\mathrm{CdCO}_{3}$ foi descartada uma vez que o $\mathrm{CO}_{2}$ foi :retirado por borbulhamento pelo $\mathrm{N}_{2}$. Os dados mostram pelas quantida des adsorvidas nas superfícies cobertas nos intervalos de pH 4 a 8 que o Cd possue alta afinidade de troca cationica. FORBES et alii (1976) estudou a adsorção es pecifica dos metais Cd, Co, Cu, P5 e $Z n$ na goetita usando a razão de $\mathrm{H}^{+}$não adsorvido pelo metal $\mathrm{M}^{2+}$ adsorvente $\left(\mathrm{H}^{+}\right.$ adsorvido/ $M^{2+}$ adsorvente). A medida do ion $H^{+}$é feita pela diferença da concentração do $H^{+}$pela ausência do ion metálico $\mathrm{M}^{2+}$ e concentração final do $\mathrm{H}^{+}$com a presença do ion 
metal $\mathrm{M}^{2}+$ Os resultados mostram que com o aumento do $\mathrm{pH}$, a adsorção se processa na seguinte ordem:

$$
\mathrm{Cu}>\mathrm{Pb}>\mathrm{Zn}>\mathrm{Co}>\mathrm{Cd} \text {. }
$$

Entretanto, as quantidades adsorvidas também aumentam com o pit em contraste com os óxidos, mostrando um comportamentodi ferente dos demais minerais.

$$
\text { LEVI-MINZI et aZii (1976) estudaram a ad- }
$$

sorção do cádmio com vảrios solos de Tuscany, em função das temperaturas, uma a $59 \mathrm{C}$ e outra a $259 \mathrm{C}$ com $\pm 0,59 \mathrm{C}$ de varia ção. Os resultados mostraram que à temperatura mais alta há maior sittio de adsorção e diminui a constante de afinida de. Outro fato a ser notado neste ensaio é, em solos com baixa CTC, baixa quantidade de matëria orgânica e alto pH, a adsorção: ë baixa, cujos valores são evidenciados pelo valor b, adsorção mảxima da equação de Langmuir que é baixo em relação a outros solos ensaiados. 0 importante deste tra balho é sugerir que as temperaturas tem infiuência na adsor ção do cādmio, provavelmente pela grande afinidade do complexo Cd-adsorvente com maior estabilidade a altas temperaturas. Nota-se que serão necessärios maiores pesquisas para melhor esclarecimentos dos resultados. 
3. MATERIAL E METODOS

\subsection{Amostras de terra}

$$
\text { As amostras de terra foram coletadas de so }
$$

los Podzólico Vermelho Amarelo-orto (PV) e Glei Húmico (GH) na região do Vale do Ribeira, no município de Juquiá, SP, no Sítio Bela Vista, Bairro Ribeirão Fundo, ambos do. Horizonte $A_{1}$. Estas amostras pertenceram a solos de uma ärea nunca cultivadas de matas virgens. A Terra Roxa Estruturada (TE) foi coletada do horizonte Ap na ärea pertencente ao Departamento de Entomologia da Escola Superior de Agricultü ra "Luiz de Queiroz" da USP no município de Piracicaba - SP em solos cultivados e adubados anteriormente a coleta da amostra. As características físicas e químicas encontra-se nas tabelas 1 e 2 . 
.16.

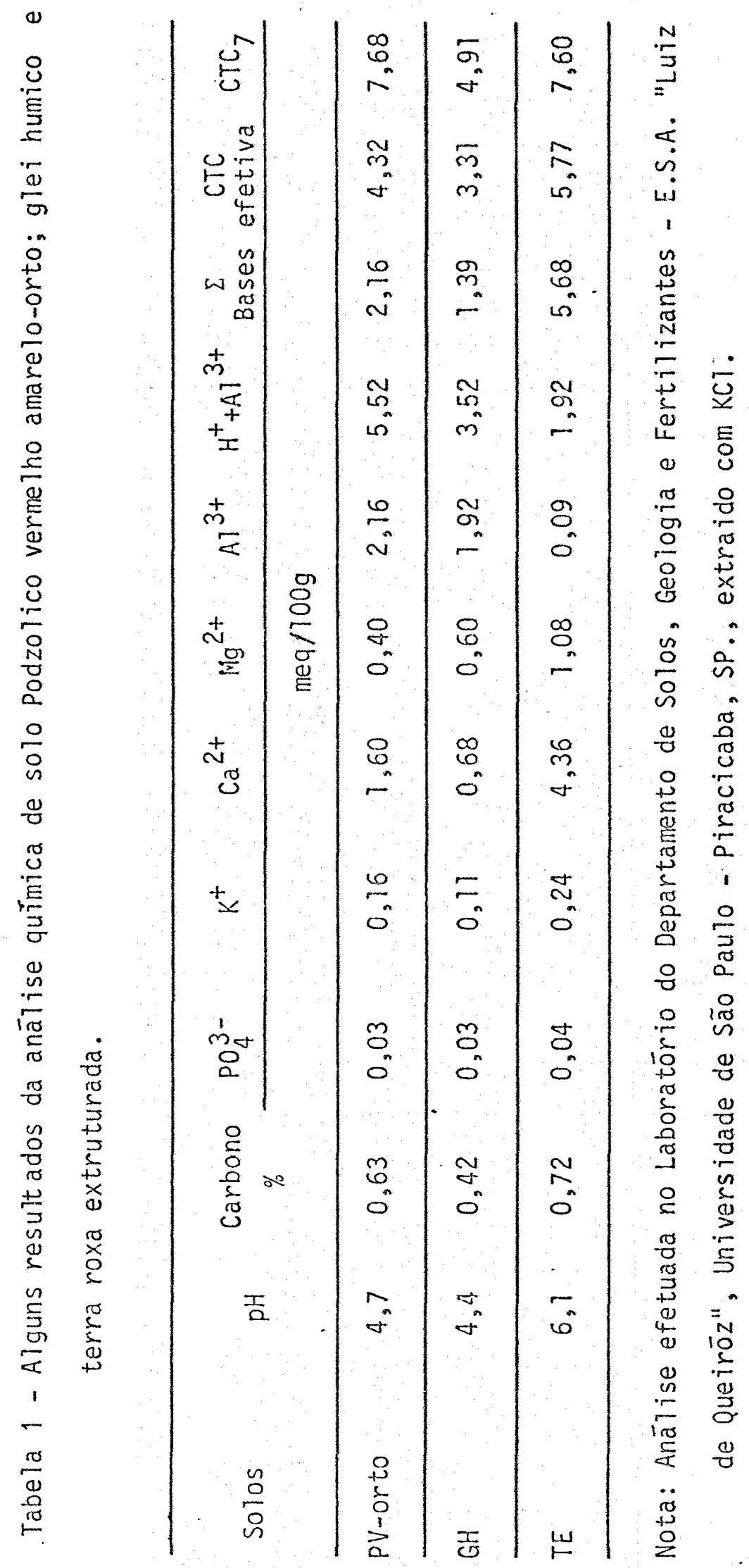


Tabela 2 - Anālise granulométrica de solos podzolico vermeTho amarelo-orto, glei humico e terra roxo estru turada.

\begin{tabular}{lccc}
\hline & Solo & Silte & Argila \\
\cline { 2 - 4 } & & $\%$ & \\
\hline PV-orto & 49,6 & 14,0 & 36,4 \\
GH & 39,6 & 17,0 & 43,4 \\
TE & 39,4 & 10,0 & 50,6 \\
\hline
\end{tabular}


Para estudo da adsorção do cádmio, foi ado tada a metodologia de John (1972) tomando-se 0,2 g de amostra de cada solo, colocando-se $10 \mathrm{ml}$ de solução de $\mathrm{CdCl}_{2}$ contendo $1 ; 5 ; 10 ; 50 ; 100 ; 250 ; 500$ e 1000 ppm de $\mathrm{Cd}^{2}+\mathrm{pa}-$ ra cada tratamento da amostra de terra. Estas amostras fo ram colocadas em agitação contínua por 16 horas a uma tempe ratura de $2790 \pm 29 \mathrm{C}$. Logo apōs a agitação foram centrifugadas e a solução sobrenadante foi analisada por espectrome tria de emissão atômica induzida por plasma. A diferença da concentração de solução inicial e final de solução de equilibrio sobrenadante considerou-se como adsorvido pela amostra de terra.

Os dados obtidos foram ajustados na equação de Langmuir na forma I inear:

$$
\frac{c}{x / m}=\frac{1}{k b}+\frac{c}{b}
$$

onde:

C è a concentração da solução de equilifbrio, $\mu g / m l$; $x / m$ e a quantidade de $C^{2}{ }^{2}$ adsorvida, $\mu g / g$ de terra;

b è a adsorção máxima, $\mu g / g$ terra;

$K$ constante de afinidade entre o adsorvente e adsor vato, $\mathrm{ml} / \mathrm{g}$. 
A razäo C/ $(x / m)$ foi calculada para cada tratamento com os valores obtidos da concentração $C$ de $C^{2}+$ em ppm da solução em equilíbrio e $x / m$ da quantidade de cädmio adsorvido pelo solo $\mu \mathrm{g} / \mathrm{g}$ de terra.

o declive da reta da equação de Lanğmuir. na forma linear, o coeficiente angular é $T / b$. A equação da reta foi calculada pelo método do mínimo quadrado programan do-se o computador Prolögica CP 500 para concentraçöes das soluções com. 5 pontos $(y \overline{5})$ de 1 a 100 ppm e com 8 pontos $\left(y_{8}\right)$ de 1 a 1000 ppm e os gräficos foram traçados pelo computador. 


\section{RESULTADOS E DISCUSSÃO}

4.1. Anālise das adsorções

A anälise dos resultados da tabela 3 e da figura 1 mostrou que há incremento na adsorção do cádmiomes mo a altas concentrações em todos os solos estudados. Entre tanto houve a adsorção acentuada de cádmio (Figura 1) na baixa concentração atë aos $\uparrow 00$ ppm em todos os solos, conforme já observado por JOHN (1972). O melhor coeficiente de correlação. $r$, na regressão l inear da equação de Langmuir na forma linear, está justamente nesta faixa até os to0 ppm de Cd, obtendo-se $r=1,00$ (Tabela 4), para os solos PV - orto e TE. Os dados ajustados no computador mostram os pontos praticamente alinhados a baixas concentrações (equação ys, 
tabela 4 e Figuras 2,4 e 6), mostrando que segue a teoria de Langmuir com a superfície adsorvida em camadas monomoleculares. As altas concentrações, pode-se notar no gráfico da figura 1, que acima dos 100 ppm é praticamente uma reta, não sendo mais uma curva, o processo de adsorção estaria nesta fase processando-se em camadas multimoleculares. A re gressão linear aplicada a equação de Langmuir na*forma li near já apresenta um coeficiente de correlação $r$ que varia de 0,89 a 0,98 , confirmando que em alguma parte da superfície de adsorção deverá estar em multicamadas ou formando ou tros complexos com o cádmio. 


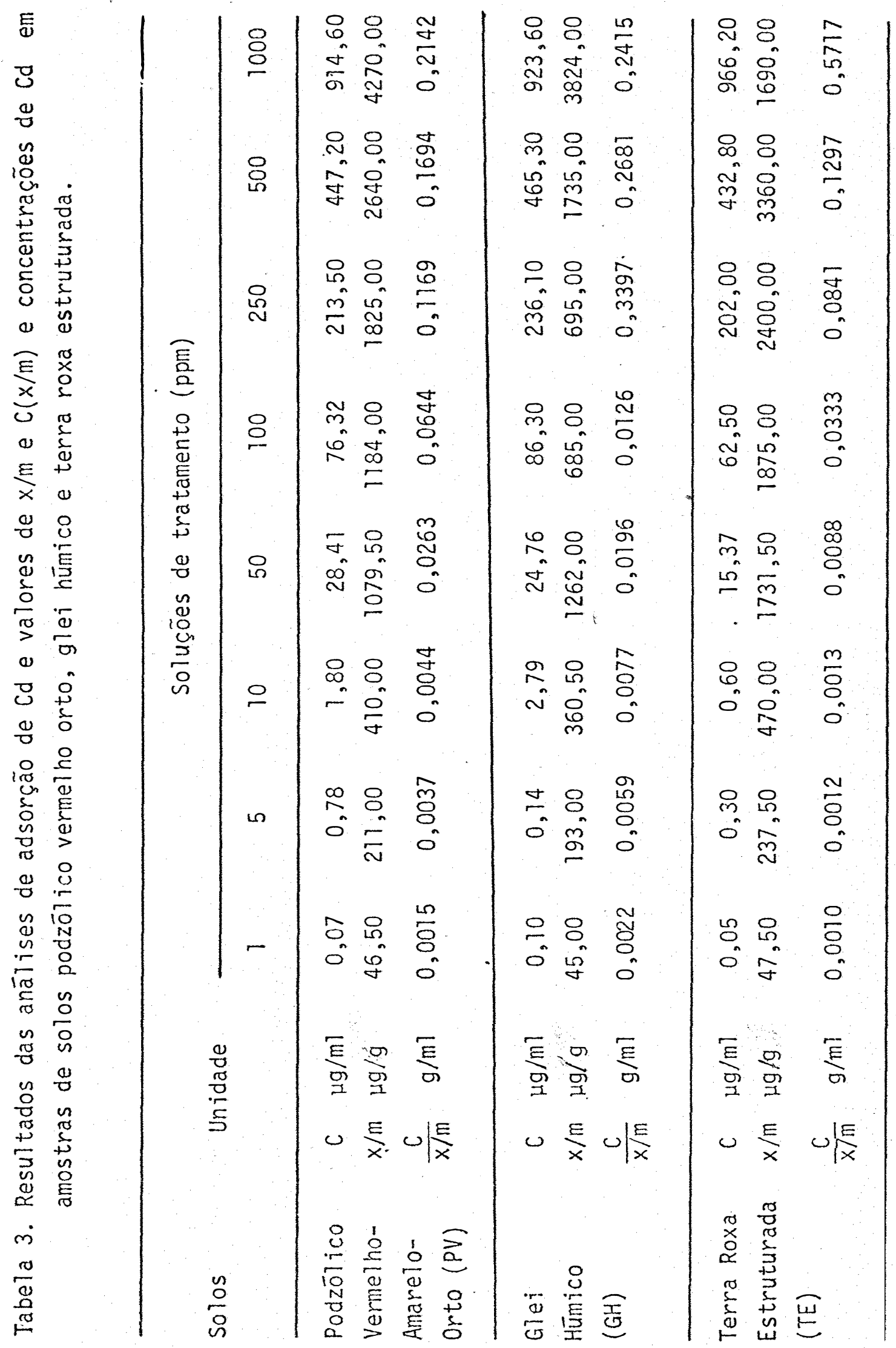




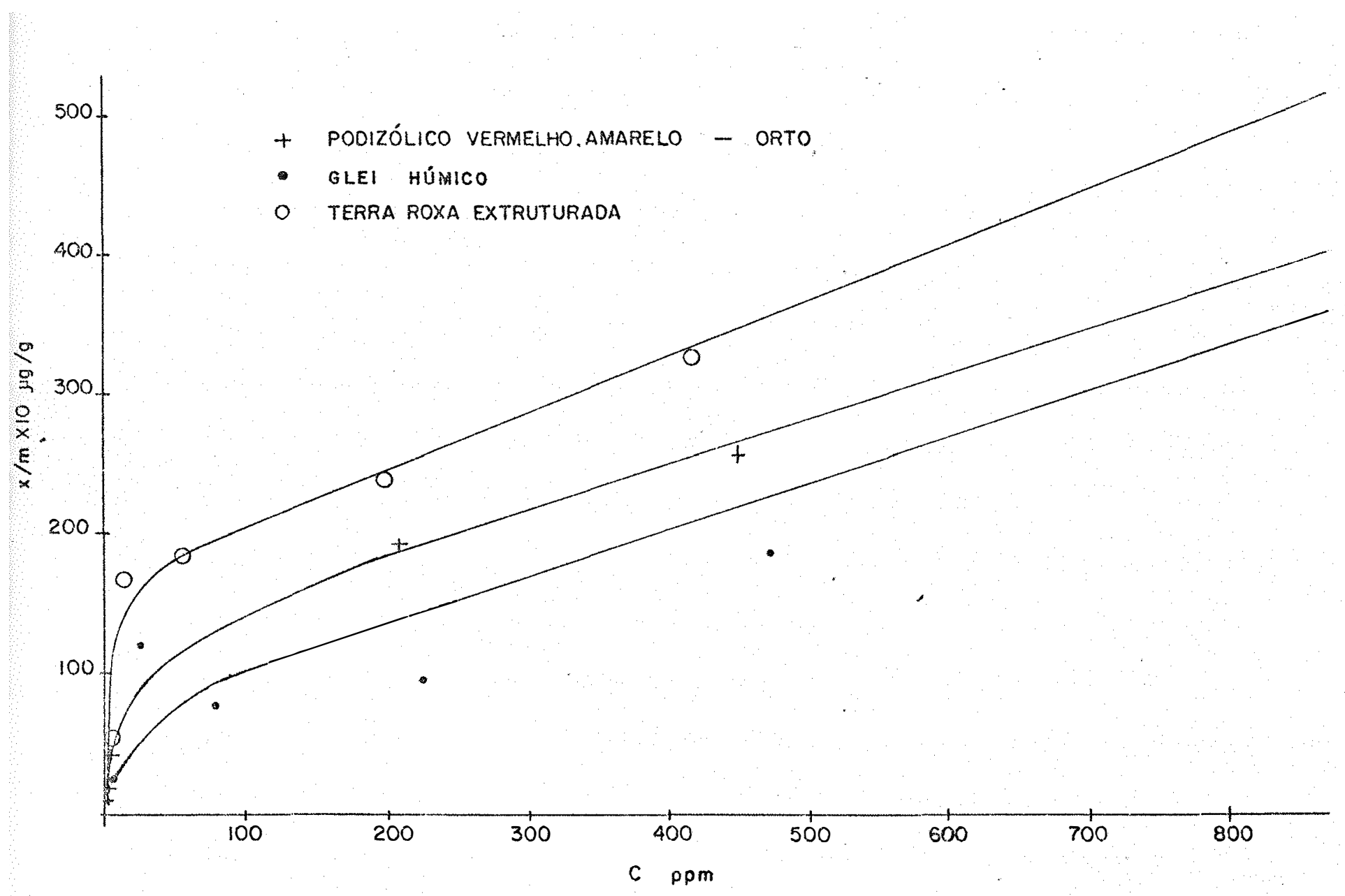

Figura 1 - Curva de adsorção de cādmio em solos Podzólico Vermetho Amarelo-orto, Gle i Hümico e Terra Roxa Estruturada em diferentes niveis de concentracão de cádmio na solucão de equí líbrio. 
4.2. Cädmio trocáve 1

A adsorção máxima de cädmio em solo PV or to a baixas concentrações (a té os $100 \mathrm{ppm}$ ). é de $2,19 \mathrm{meq} / 100 \mathrm{~g}$ TFSA (Tabela 4, equação y e figura 2). Este valor é aproximadamente igual a $\sum$ Base (Tabela 1 ), o que significa que o $\mathrm{Cd}^{2+}$ poderá competir com as principais bases $\mathrm{Ca}^{2+}, \mathrm{Mg}^{2+} \mathrm{e} \mathrm{K}^{+} \mathrm{e}-$ xistente no solo. O gráfico da regressão linear na figura 2, da equação de Langmuir com o coeficiente $r=1,00$, sugere que a adsorção de cádmio pode ser descrita perfeitamente pe la equação de Langmuir. As altas concentrações até os 1000ppm o $\mathrm{Cd}^{2+}$ trocável é de $7,43 \mathrm{meq} / 100 \mathrm{~g}$ TFSA (equação $y_{8}$, Tabela 4 e Figura 3). Este valor teria condições de estar competin do com todas as bases, inclusive com $\mathrm{Al}^{3+}$. A porcentagem em saturação de $\mathrm{Cd}^{2}{ }^{+}$trocável em relação a CTC efetiva é $50,7 \%$ a baixa concentração de $171,9 \%$ na alta concentraçãdTa bela 5). Em relação a $\operatorname{CTC}_{7},-\bar{e}$ de $28,5 \%$ na baixa concentração e $96,7 \%$ na alta concentração. Nesta concentração o $C^{2+}{ }^{2+}$ trocável não supera os cátions do solo. A existência da com

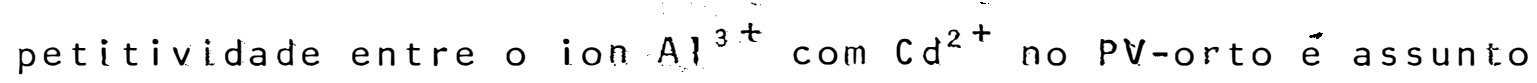
de pesquisa com níveis diferentes de $\mathrm{pH}$.

\section{As baixas concentrações até $100 \mathrm{ppm}$ o solo} GH apresenta adsorção máxima de $1,94 \mathrm{meq} C \mathrm{C} / 100 \mathrm{~g}$ TFSA (Tabe . la 4 equação $y_{5}$ e Fígura 4 ), e este valor mostra que o Cd estä competindo com todas as bases $\mathrm{Ca}^{2+}, \mathrm{Mg}^{2+}$ e $\mathrm{K}^{+}$que é de 


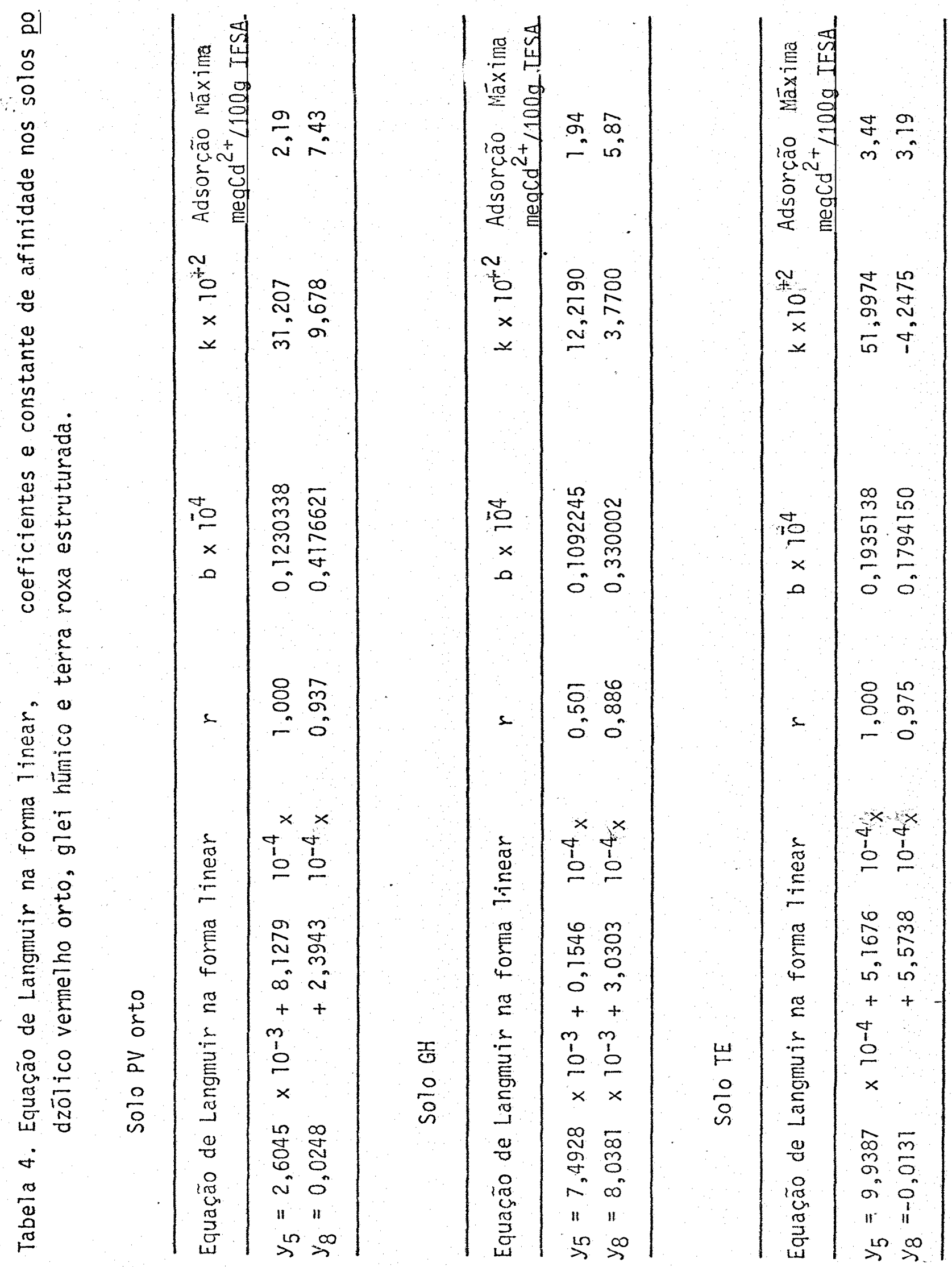




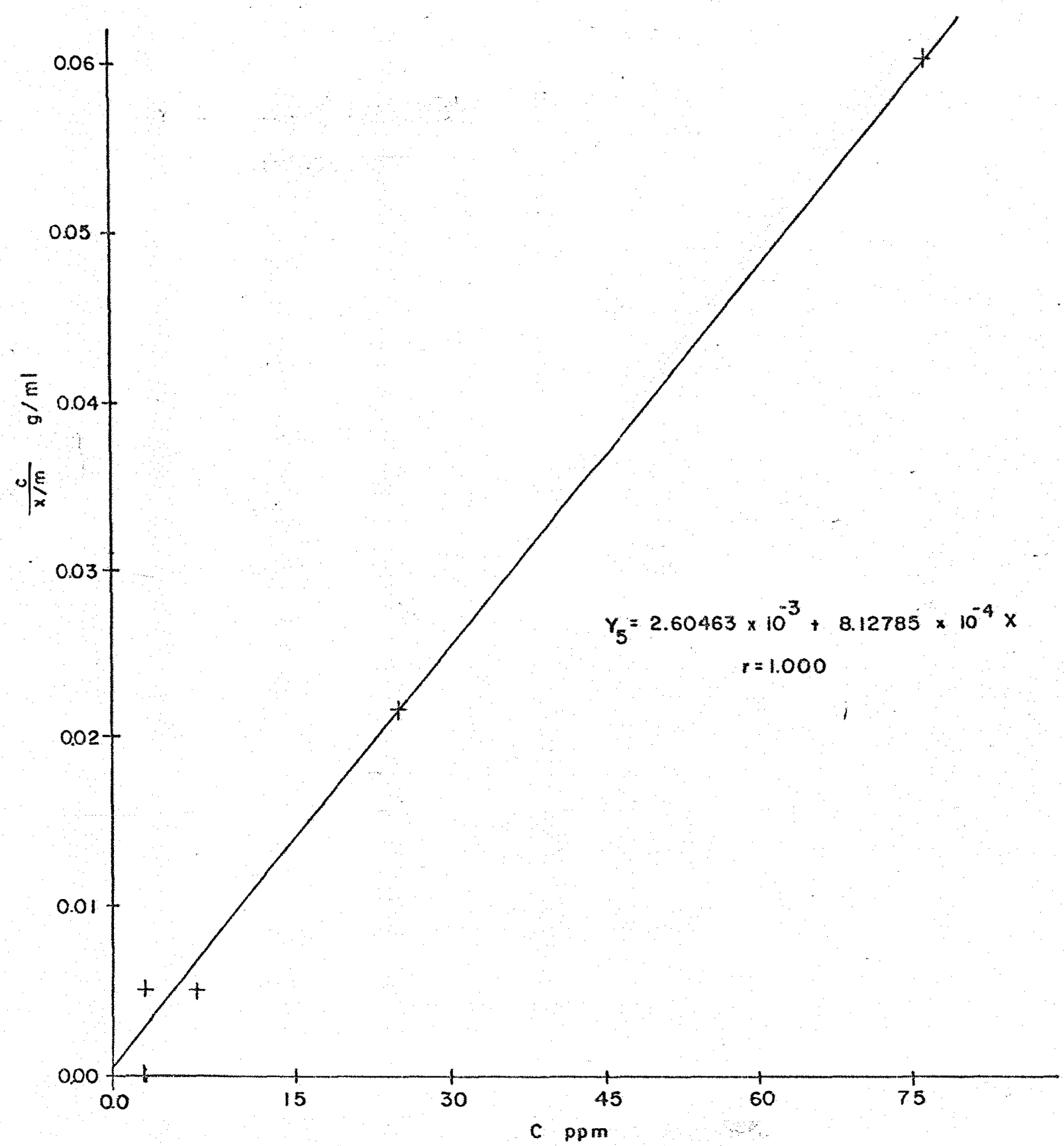

Figura 2 - Regressão Tinear da equação de Langmuir $C /(x / m)$ vs. C com 5 pontos a baixa concentracão em so. 10 PV orto. 


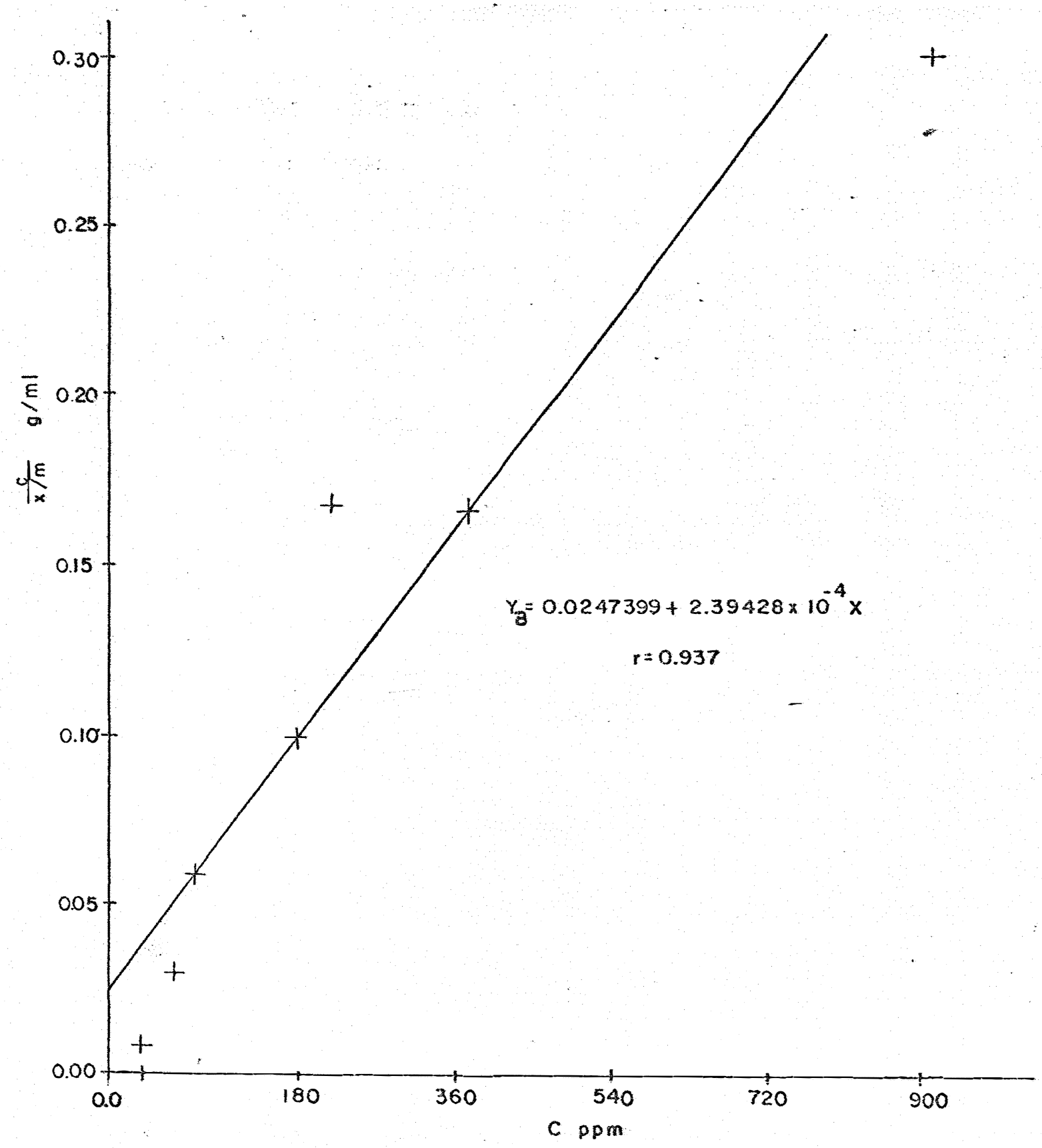

Figura 3 - Regressão linear da equaçäo de Langmuir $C /(x / m)$ vs. C com 8 pontos em solo PV orto. 
Tabela 5. Relação de saturação $\% C d^{2+}$ trocāvel vs. CTC efeti va e $\% \mathrm{Cd}^{2+}$ vs $\mathrm{CTC}_{7}$.

\begin{tabular}{|c|c|c|c|c|}
\hline \multirow[b]{2}{*}{ Solo } & \multirow{2}{*}{ Equação } & \multirow{2}{*}{$\begin{array}{c}\mathrm{Cd}^{2+} \text { Trocave } 1 \\
\text { meq } / 100 \mathrm{~g}\end{array}$} & \multicolumn{2}{|c|}{ Saturação $C d^{2+}$ trocāvel, \% } \\
\hline & & & CTC efetiva & $\mathrm{CTC}_{7}$ \\
\hline \multirow[t]{2}{*}{ PV orto } & $y_{5}$ & 2,19 & 50,7 & 28,5 \\
\hline & $y_{8}$ & 7,43 & 171,9 & 96,7 \\
\hline \multirow[t]{2}{*}{$G H$} & $y_{5}$ & 1,94 & 58,6 & 58,0 \\
\hline & $y_{8}$ & 5,87 & 177,3 & 119,5 \\
\hline \multirow[t]{2}{*}{ TE } & $y_{5}$ & 3,44 & 59,6 & 45,2 \\
\hline & $y_{8}$ & 3,19 & 55,2 & 41,9 \\
\hline
\end{tabular}




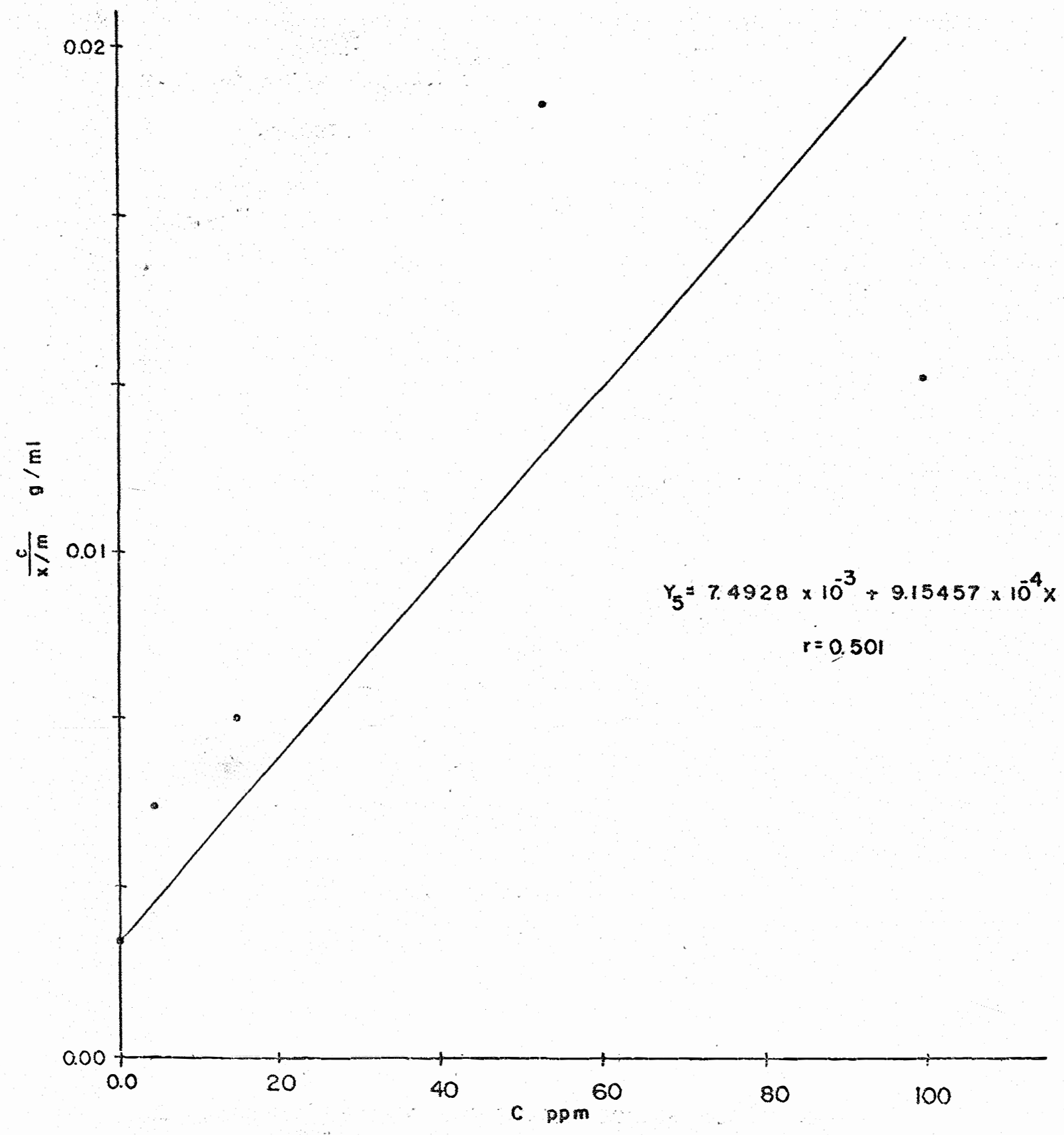

Figura 4 - Regressão 1 inear da equacão de Langmuir $C /(x / m)$ vs. C com 5 pontos em baixa con centração no solo Glei Hümico. 


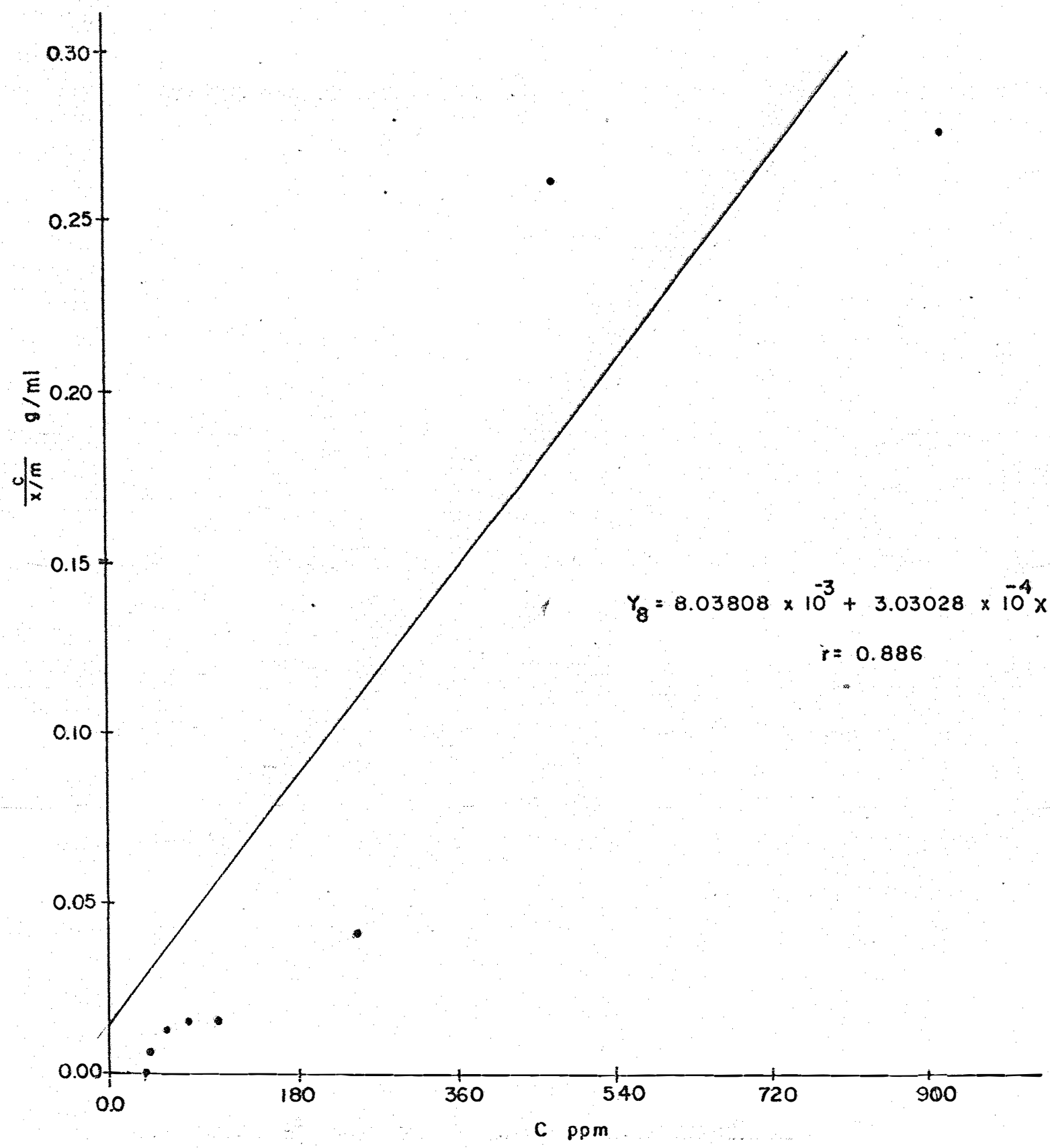

Figura 5 - Regressão 1 inear da equação de Langmuir $\mathrm{C} /(\mathrm{x} / \mathrm{m})$ vs. C com 8 pontos em solo Glei Hümico. 
1,39 meq/100g TFSA neste solo (Tabela 1). A altas concentra çoes (atè $1000 \mathrm{ppm}$ ) o $\mathrm{Cd}^{2+}$ trocävel è de $5,87 \mathrm{meq} / 100 \mathrm{~g}$ TFSA (Tabela 4, equação yo e Figura 5) cujo valor é superior a CTC efetiva e $\mathrm{CTC}_{7}$, estando portanto competindo com $\mathrm{Al}^{3}{ }^{+} \mathrm{e} \mathrm{H}^{+}$, ou formando complexos $\mathrm{Al}(\mathrm{OH})_{3}-\mathrm{Cd}$. A determinação exata do complexo - Cd é difícil de precisar, devida a metodologia a plicada na anălise do cädmio no presente trabalho. A porcen tagem correspondente ao $C^{2 t}$ trocável em relação a CTC efetiva é de $58,6 \%$ a baixa concentração (até 100 ppm). Em rela ção a $\mathrm{CTC}_{7}$ a porcentagem é $58,0 \%$ a baixa concentração (até 100 ppm) e $119,5 \%$ a alta concentração (até 1000 ppm). Este valor indica que estä acima da CTC, do solo GH. As causas poderão ser a precipitação do cădmio ou formação do complexo-Cd devido ao silte. Entretanto, na equação de Langmuir na regressão linear matematicamente estâ satisfatöria, com um coeficiente de correlação $r=0,886$ (Figura 5). Para elú cidação das causas necessita-se de maior pesquisa para esclarecer esta discrepância. Descartando a hipötese de que não haja precipitação ou complexo - c d, é um solo que apresenta alto risco de contaminação por este metal tóxico.

O solo TE è o que apresenta maior adsorção mäxima de cädmio entre os três solos pesquisados com $3,44 \mathrm{meq} \mathrm{Cd/100g} \mathrm{TFSA} \mathrm{(Tabela} 4$, equação $y_{5}$, Figura 6) a baixas concentrações, entretanto competiu somente com uma parte das bases $\mathrm{Ca}^{2 t}, \mathrm{Mg}^{2 t}$, e $\mathrm{K}^{t}$ deste solo, cuja $\Sigma$ Bases é 


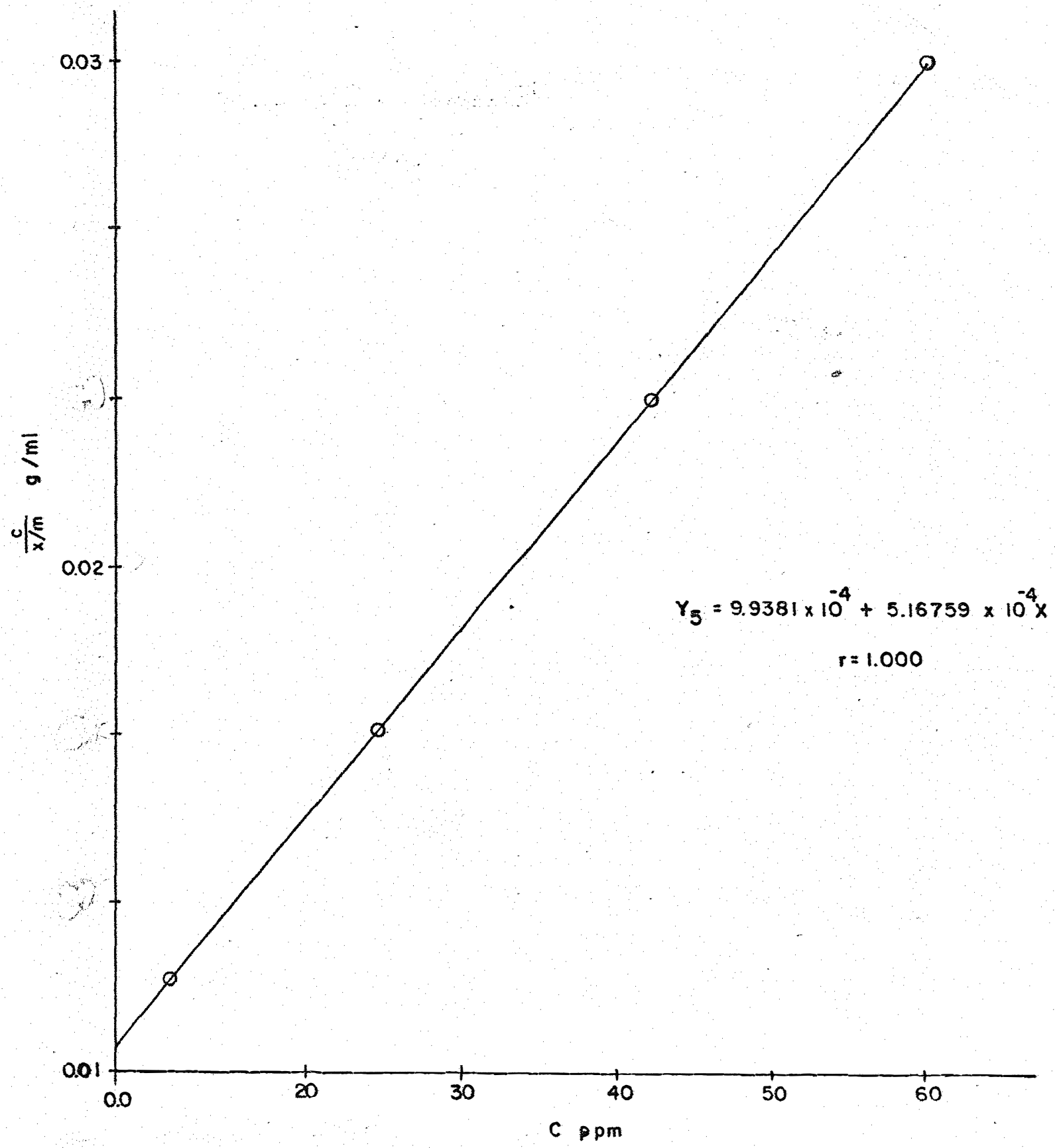

Figura 6 - Regressão 1 inear da equacão de Langmuir $\mathrm{C} /(\mathrm{x} / \mathrm{m})$ vs. C com 5 pontos a baixa concentração em solo TE. 


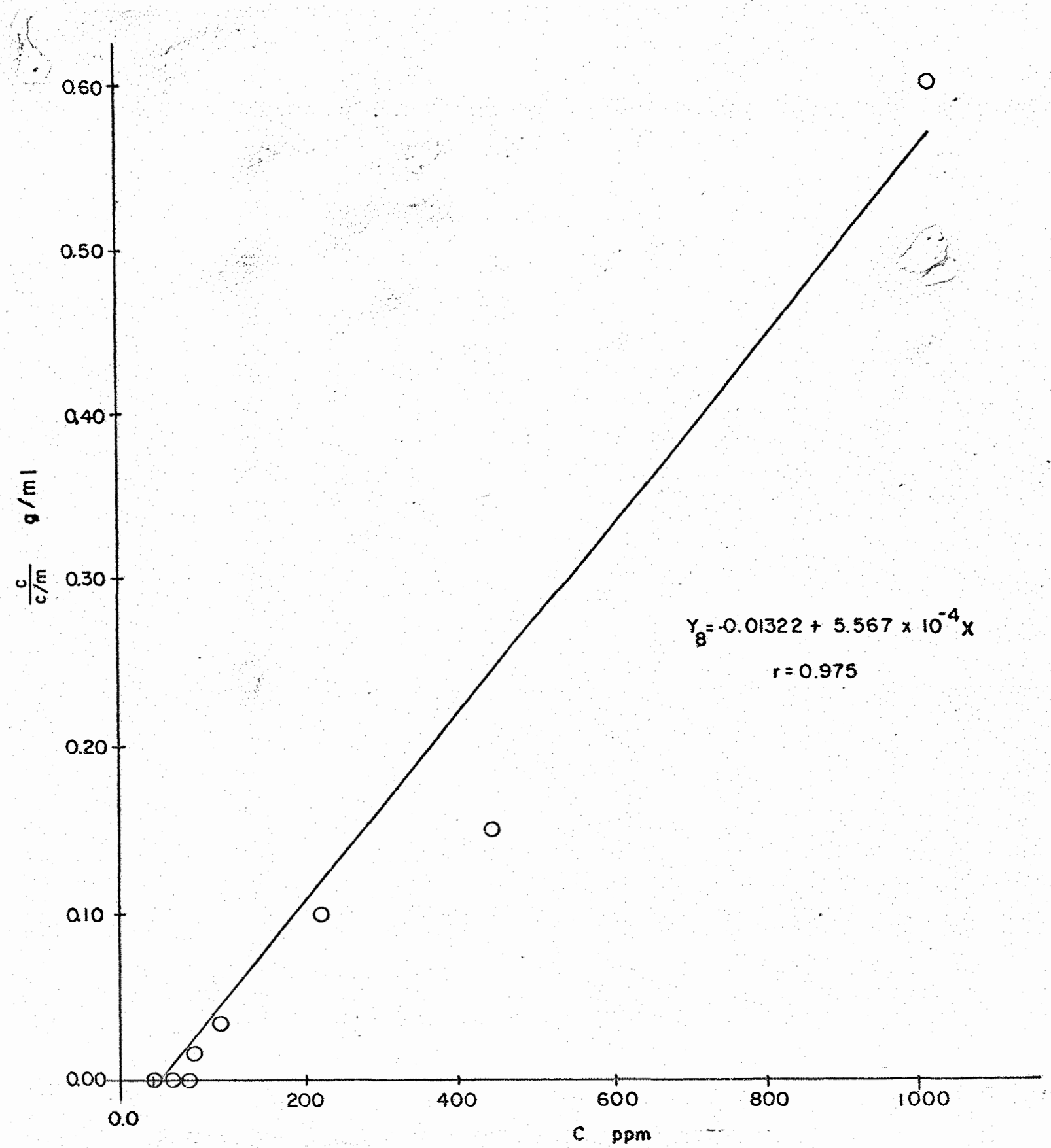

Figura 7 - Regressão linear da equacão de Langmuir $C /(x / m)$ vs. C com 8 pontos em solo TE. 
$5,68 \mathrm{meq} / 100$ TFSA (Tabela 1). A altas concentrações (até

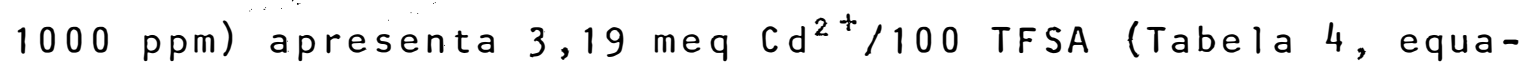
ção $y_{8}$ e Figura 7), valor menor do que a baixas concentrações (até $100 \mathrm{ppm}$ ). A regressão linear se apresenta matematicamente perfeita, tendo o coeficiente de correlação $r=0,975$ (Figura 7), significado que os valores dos pontos, obtidos seguem a equação de Langmiuir. Portanto as adsorções, neste solo talvez sejam por processo não iônico ou houve precipi tação do complexo - Cd em cuja metodologia empregada para a nálise do Cd não foi possível de ser detectada. Uma vez que o coeficiente de correlação $\bar{e} r=0,975$ a precipitação pode rá ser descartada, caso conträrio haveria um desvio muito grande. 0 que se pode conjecturar, é na medida que aumenta a concentração do Cd há uma adsorção gradativa pelos hidróxidos de $\mathrm{Al}(\mathrm{OH})_{3}=\mathrm{Cd}$ e $\mathrm{Fe}(\mathrm{OH})_{3}-\mathrm{Cd}$. Os trabalhos de CHUBIN e STREET (1981) mostram que em pH 6, as adsorções em hidróxidos de alumínio e ferro são maiores. A anālise da amostra desta terra indica o pH 6,1 (Tabela 1) e neste solo è baixíssimo o teor de $\mathrm{Al}^{3}$. Provavelmente as adsorções sejam no complexo do hidróxido de ferro - cảdmio. Necessita-se de maior pesquisa para melhor esclarecer a ocorrência desta ad sorção neste solo. Em relação a porcentagem de $\mathrm{Cd}^{2+}$ :trocävel apresenta $45,2 \%$ a baixa concentração e $41,9 \%$ na alta concentração (Tabela 5). Nota-se que este solo è o que apre senta menor grau de toxidez a planta em caso de contamina- 
ção maciça, não chegando a $50 \%$ de adsorção em relação a CTC $_{7}$ ou efetiva. Entretanto, é necessário uma pesquisa sobre o aspecto da lixiviaça para outros tipos de riscos de contaminação como de lençol freático. 
.36 .

\section{CONCLUSĀO}

Com base nos resultados, as principais con clusões da adsorção são as seguintes:

- A aplicabilidade da equação de Langmuir na adsorção de Cd em todos os solos é a baixas concentrações at $\vec{e}$ os 100 ppm ;

- As altas concentrações as correlações matemä́ticas apresen tam-se boas para todos os solos tendo para os solos PV-or to e Glei Hūmico possíveis adsorções iônicas;

- Os solos que apresentam maior competição do cãdmio, as principais bases trocáveis nos solos, são o PV-orto e GH competindo inclusive com $\mathrm{Al}^{3+}$ e $\mathrm{H}^{+}$; 
- O solo com menor risco da toxidez à planta é o TE apresen tando $41,9 \%$ de $C^{2} d^{2}$ trocável em relação a CTC 7 enquanto que os demais solos estão de $96,7 \%$ a $119,5 \%$;

- O solo de maior risco de toxidez à planta è o Glei Húmico, tanto a baixa como a altas concentrações do cädmio;

- A adsorção de Cd nos solos diminui na seguinte ordem:

$$
\text { PV-orto }>G H>T E \text {. }
$$


.38 .

\section{LITERATURA CITADA}

BRADY, B. E G.K. PAKEMKOPF, 1978. Cadmium complexation by soil fulvic acid. Can, J. Chem, 56:2331-2335.

CHUBIN, R.G. e J.J. STREET, 1981. Adsorption of Cadmium on soil constituents in the presence of complexing ligands. J. Environ. Qual., 10, 225-228.

DAVIS, J.A. e J.O.L. LECKIE, 1978. Effect of adsorbed complexing ligands on trace metal uptake by hydrous oxides. Environ, Sci. Technol, 12: 1309-1315.

ELLIOT, H.A. e C.M. DENNENY, 1982. Soil adsorption of Cadmium from solutions containing organic ligands. J. Environ. Qual., vol, 11, n? : 658-663. 
FORBES, E.A.; A.M. POSNER E J.P. QUIRK, 1976. The specific adsorption of divalent $\mathrm{Cd}, \mathrm{Co}, \mathrm{Cu}, \mathrm{Pb}$ and $\mathrm{Zn}$ on Goethite. J. Soil Sci., $27: 154-166$.

GARCIA-MIRAGAYA, J. e A.L. PAGE, 1976. Influence of ionic strength and inorganic complex formation on the sorption of trace amounts of Cd by montmorillonite. Soil Sci. Soc. Am. J., $40: 658-663$.

INSKEEP, W.P. e J. BAHAN, 1983. Adsorption of Cd (11) and $\mathrm{Cu}$ (11) by $\mathrm{Na}$ - Montmorillonite at low surface coverage. Soil Sci., Am. J., $47: 660-665$.

JOHN, M.K., 1972. Cadmium adsorption maxima of soils as measured by the Langmuir isotherm. Can J.Sci., $52: 343-350$.

LAGERWERFF, J.V. e SPECHT, A.W., 1970. Contamination of roadside soil and vegetation with cadmium, nickel, lead and zinc. Environ. Sci. E Tech., 4:583-586.

LAGERWERFF, J.V., 1972. Lead, mercury and cadmium as environ mental contaminants. In: Micronutrients in Agriculture, edited by J.J. Mortvedt, P.M. Giordand and W.L. Lindsay. Soil Science Society of America, Inc. UDA. 666p. 
LEVI-MINZI, G.F.; G.F. SOLDANTINI e R. RIFFALDI, 1976. Cadmium adsorption by soil. J. Soil Science, $27: 10-15$.

MENGEL, K. e KIRKBY, E.A., 1978. Principles of plant nutrition. International Potash Institute, 2 a ed. Bern Suica, 509-520.

MILBERG, R.P.; D.L. BROWER e J.V. LAGERWARFF, 1978. Exchange adsorption of trace quantities of cadium in soils treated with calcium and sodium: a reapprosal. Soil. Sci. Soc. Am. J., $42: 892-894$.

OLSEN, S.R. e WATANABE, F.S., 1957. A method to determine a phosphorus adsorption maximum of soils as measured by the Langmuir isotherm. Soil Sci. Soc. Amer. Proc., $21: 144-149$.

PAGE, A.L. e F.T. BINGHAM, 1973. Cadmium residues in the environment. Residues Rev., $48: 1-44$.

REUS, J.; H.L. DOOLEY e W. GRIFFIS, 1976. Plant uptake Cd from phosphate fertilizer. Enviromental protection agency, PB $255: 314$. 
SCHOROEDER, H.A., 1965. Chromium, Cd and lead in rats. Effects in life span, tumors and tissue levels.J. Nutr., $86: 51$.

SCHOROEDER, H.A., 1965. Cadmium as a factor in hypertension. J.Chromic. Dis., $18: 647-656$.

SCHOROEDER, H.A. e J.J. BALASSA, 1961. Abnormal trace metals in man: cadmium. J. Chronic. Dis., 14:236-258.

SLOYAN, P.J., 1971. Mercurio: novo agente poluidor. In: Atualidade científica - Jornal "O Estado de São Paulo" Edi ção do dia $29 / 08 / 71, p g * 174$.

TAKAMATSU, T, e T, YOSHIDA, 1978. Determination of stability constants of metal-humic acid complex by potentiometric titration and ion-selective eletrodes. Soll. Sci. $125: 377-386$.

WHITTON, B.A., 1975. Studies in ecology, vol. 2. River Ecology, pp. 286-311. Ed, Whitton, B.A.; publ. Blackenell Scientific Publication. Applied Ecology Abstracts, vol, 3. 1977. 